\title{
Spindle-Cell Lesions of the Breast with Emphasis on the Differential Diagnosis
}

\author{
Shi Wei ${ }^{1}$ and Omar Hameed ${ }^{*}, 1,2,3$
}

\author{
${ }^{1}$ Department of Pathology, ${ }^{2}$ Department of Surgery, and ${ }^{3}$ The Comprehensive Cancer Center, University of Alabama at \\ Birmingham, Birmingham, AL, USA
}

\begin{abstract}
Compared to epithelial lesions, spindle-cell lesions of the breast are relatively uncommon and, because of that, may cause diagnostic difficulty. The majority of these spindle cell lesions, such as fibromatosis, nodular fasciitis, spindlecell carcinoma, inflammatory myofibroblatic tumor and angiosarcoma, resemble their more common non-mammary counterparts. A few others, such as pseudoangiomatous stromal hyperplasia for example, specifically arise in breast. This review discusses these mammary spindle cell lesions with a focus on their salient histological features.
\end{abstract}

Keywords: Breast, carcinoma, spindle cell, fibromatosis, nodular fasciitis, pseudoangiomatous stromal hyperplasia, myofibroblastoma, inflammatory myofibroblastic tumor, reactive spindle cell nodule, angiosarcoma.

\section{INTRODUCTION}

Although spindle cell lesions of the breast represent only a small proportion of breast lesions, they encompass a diverse group ranging from reactive to neoplastic, highly malignant processes. Especially with the advent of small needle core biopsy procedures, accurate diagnosis of such spindle lesions can sometimes be quite challenging. Most of them can be appreciated on routine hematoxylin and eosin (H\&E)-stained sections; nevertheless, a certain proportion of cases require ancillary studies such as immunohistochemistry (IHC) to arrive at a correct diagnosis. One such example is metaplastic spindle cell carcinoma, which, because of the management implications, is arguably the most important spindle-cell lesion of the breast to recognize. This review focuses on the histologic characteristics of breast lesions that are almost exclusively composed of spindle cells, with emphasis on the pathologic differential diagnosis. Given their unique fibroepithelial nature, fibroadenomas and phyllodes tumors will not be covered.

\section{Fibromatosis}

Mammary fibromatosis (MF) is a rare entity accounting for less than $0.2 \%$ of primary breast tumors [1]. Most cases are sporadic, but others develop after trauma or a surgical procedure; some cases may also be seen in association with familial adenomatous polyposis (FAP) syndrome, an autosomal dominant inherited disease [1]. Like its soft tissue counterpart described extensively in the trunk and the extremities, MF is an infiltrative, locally aggressive but nonmetastasizing lesion with a high propensity for local recurrence [2]. These lesions are often palpable and appear as spiculated, ill-defined masses mammographically that may resemble infiltrative carcinoma.

Similar to fibromatosis elsewhere, the histologic appearance of MF consists of an irregular proliferation of variably

*Address correspondence to this author at the Department of Pathology, NP 3550, University of Alabama at Birmingham, 619 South 19th Street, Birmingham, AL 35294-6823, USA; Tel: 205-996-5848; Fax: 205-9755242; E-mail: ohameed@uab.edu cellular, low-grade spindle cells that usually extend into or entrap surrounding fat and glandular elements [2]. The cellular proliferation may be arranged in interlacing long sweeping fascicles, a storiform pattern, or a herringbone configuration, often with increased cellularity at the periphery. The intervening stroma is variable and can appear myxoid in nature, resembling nodular fasciitis, or more collagenized including florid cases with keloid/tendon-like collagen deposition, hence the other term used to describe fibromatosis, desmoid tumor (the term desmoid is derived from the Greek word desmos, which means tendon-like). The individual lesional cells have indistinct cell borders with pale, eosinophic cytoplasm and oval to elongated nuclei with tapering ends (Fig. 1). Mitotic figures are inconspicuous or not discernable. Consistent with its presumed myofibroblastic derivation, there is at least focal smooth muscle actin (SMA) expression by IHC in the lesional cells. Like fibromatosis at other sites, nuclear accumulation of $\beta$-catenin by IHC is present in most cases of MF, both sporadic and familial adenomatous polyposis-associated; [3] nevertheless, lack of nuclear expression does not rule out the diagnosis.

The most important entities often encountered in the differential diagnosis of MF are scar, fibromatosis-like spindle cell carcinoma, and, less likely, sarcoma. The presence of findings commonly seen in association with trauma or surgical intervention; such as hemosiderin deposition, fat necrosis, foamy macrophages, and foreign body giant cells, supports a diagnosis of scar. A fascicular growth pattern and entrapment of breast parenchyma are not common features seen in a scar. However, the distinction of residual fibromatosis from postoperative scar may be extremely difficult and sometimes impossible. Increased cellularity, nuclear pleomorphism, frequent mitoses, and absence of demoid-like foci are generally clues to the diagnosis of a malignant spindle cell tumor. In such cases, IHC stains using a number of epithelial markers, as discussed below, may be required to rule out a metaplastic carcinoma. Pure spindle cell sarcomas are extremely rare in the breast and usually demonstrate hypercellularity, nuclear 
(a)

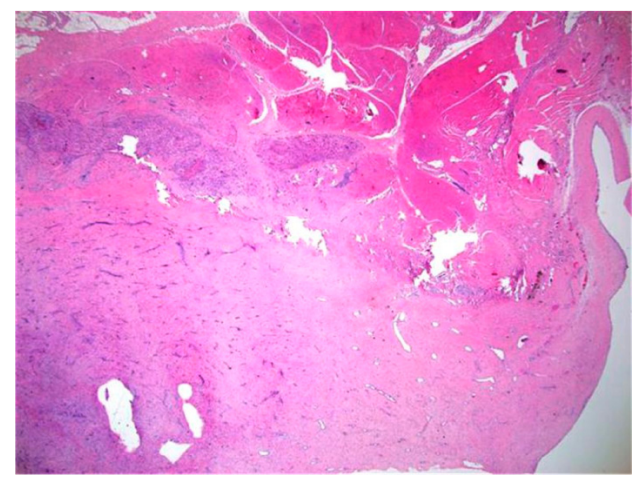

(b)

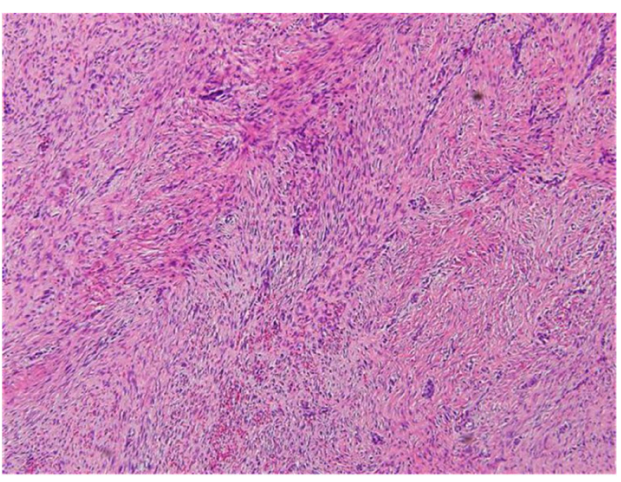

(c)

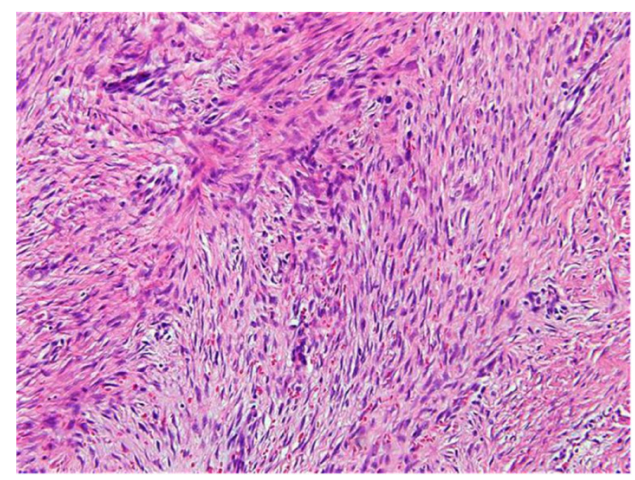

(d)

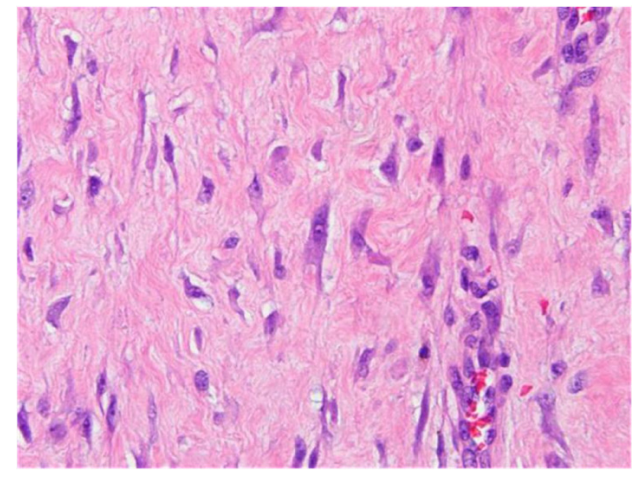

Fig. (1). Mammary fibromatosis. This lesion is seen adherent to the skeletal muscle (upper third of image) (a) and is composed of fascicles of spindle cells (b) with minimal pleomorphism (c); nevertheless, occasional atypical cells may be identified (d) [hematoxylin and eosin, original magnification X20 (a); X100 (b); X200 (c); X600 (d)]. plemorphism and mitotic activity, including atypical forms. Because of these differential diagnostic considerations, the definitive diagnosis of $\mathrm{MF}$ is difficult or impossible in limited biopsy samples and often requires excisional biopsy.

\section{Nodular Fasciitis}

Nodular fasciitis (NF) is a benign myofibroblastic/fibroblastic proliferation that usually presents as a solitary and rapidly growing mass. It typically affects subcutaneous tissue of the upper extremities in young adults, although it may appear at any site and in any age [4]. While its etiology remains unknown, NF is considered a self-limiting, reactive process rather than a true neoplasm, as its natural history is that of spontaneous involution over a period of several months. Nodular fasciitis is uncommonly seen in the breast but may cause diagnostic difficulties because of its clinical and radiological presentation as a mass lesion and its histologic pseudosarcomatous appearance [2]. Nodular fasciitis may be located in the breast parenchyma, the underlying chest wall or in the adjacent subcutaneous tissue [2].

The histologic appearance is usually that of a wellcircumscribed but non-encapsulated lesion composed of plump myofibroblasts in its early stage. Mammary ducts and lobules are usually pushed aside and not present within the lesion. The lesional cells may be arranged in short fascicles and whorls resembling fibroblasts grown in tissue culture, and frequently in a zonal distribution with increased cellularity at the periphery (Fig. 2). The stroma is typically myxoid and may contain microcysts. Mitotic figures may be numerous but there are no atypical forms. There are variably sized nucleoli but nuclear hyperchromasia is absent. Necrosis is not a feature of NF. Other features that are often seen in NF and are helpful for the diagnosis include extravasated erythrocytes, patchy lymphoid infiltrates, and a granulation tissue-like prominent vasculature. Scattered osteoclast-like giant cells may also be present. As the lesion ages, it generally becomes less cellular with variable stromal collagen deposition [2, 4].

Given its cellularity, mitotic figures and rapid growth, NF (both in the breast and elsewhere) may be mistaken for a malignant spindle cell tumor, especially on needle biopsy. The presence of numerous mitotic figures may be worrisome, but, as noted above, the absence of atypical mitoses, nuclear atypia or cellular pleomorphism, almost invariably present in sarcomas and most metaplastic carcinomas, should help point to the correct diagnosis. The absence of cytokeratin expression is also very helpful in this regard. Another differential diagnostic consideration is fibromatosis. Nodular fasciitis does not have the latter's long, sweeping fascicles. In addition, frequent mitoses are typically found in NF but are not a feature of fibromatosis. It is particularly important to be aware that IHC should be interpreted with caution in this setting. Given the myofibroblastic origin of NF and fibromatosis, both may focally or diffusely express SMA, thus potentially leading to its misdiagnosis as a myofibroblastic or myogenic neoplasm.

\section{Spindle Cell Carcinoma}

Spindle cell carcinoma refers to a group of invasive carcinomas with a pure or predominant spindle cell 
(a)

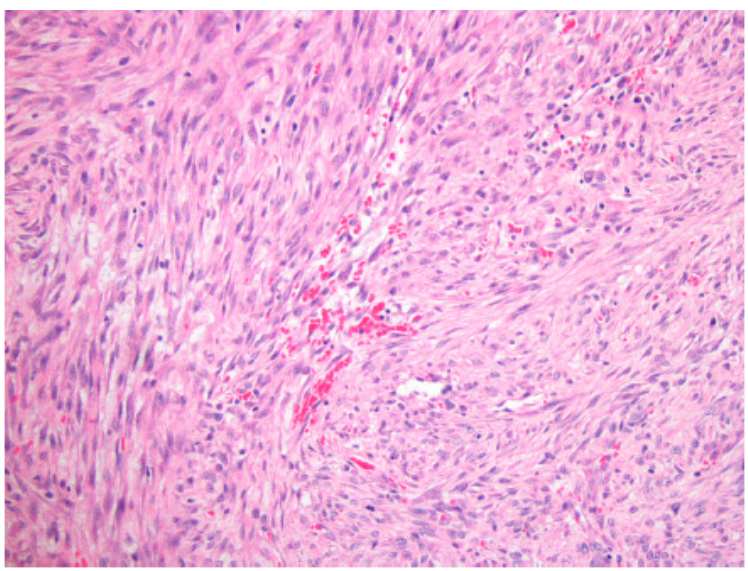

(b)

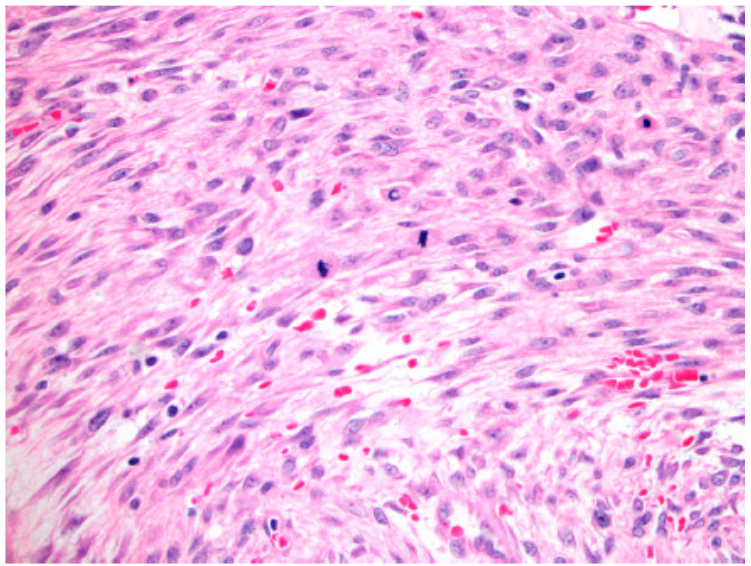

Fig. (2). Nodular fasciitis. This lesion is composed of plump myofibroblasts/fibroblasts without atypia, with a tissue-culture like growth pattern (a). The lesion has a focal mucoid stroma, RBC extravasation, and frequent mitotic figures (center) without atypical forms (b) [hematoxylin and eosin, original magnification X100 (a); X400 (b); images courtesy of Dr. Margaret Brandwein-Gensler, Birmingham, AL).

component, and is traditionally included within the broader category of metaplastic carcinoma $[2,5]$. It comprises less than $1 \%$ of all invasive breast carcinomas, but represents a significant diagnostic challenge, especially in needle core biopsy material [6].

There is a wide spectrum in the histomorphologic appearances of spindle cell carcinoma. The tumor may have a fascicular, storiform, or haphazard growth pattern with infiltrative borders. The tumor cells vary from cytologically bland to highly pleomorphic. These lesions can be largely divided into two groups: biphasic and monophasic [5]. The biphasic tumors consist of both a carcinomatous component and a sarcomatoid component resembling any mesenchymal sarcoma such as fibrosarcoma, chondrosarcoma or osteosarcoma (Fig. 3). Because of the presence of a carcinomatous component, the diagnosis of such biphasic tumors is relatively straightforward. At the other end of the spectrum are tumors almost exclusively composed of spindle cells (hence termed "monophasic") (Fig. 4). The lesional cells may also have variable cellular pleomorphism and, rarely, areas of squamous differentiation. In some monophasic tumors, rare/subtle foci of malignant epithelial islands or ductal carcinoma in-situ (DCIS) may be present, providing evidence supporting the epithelial nature of the tumor. One should note, however, that even biphasic tumors can lack an epithelial component in small biopsy specimens, and other spindle cell malignancies, such as malignant phyllodes tumor and sarcomas should also be given serious diagnostic consideration.

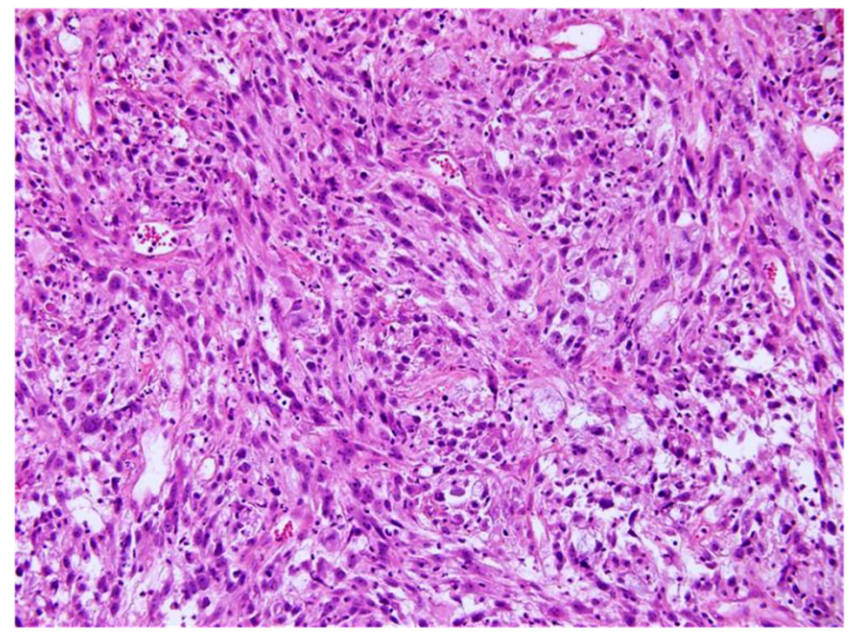

Fig. (3). Sarcomatoid carcinoma. This tumor is composed of markedly atypical spindle cells; areas of unequivocal epithelial differentiation were present elsewhere (hematoxylin and eosin, original magnification X200).

Because of the absence or the focal presence of morphological evidence of epithelial differentiation in some cases of spindle cell carcinoma, the immunohistochemical expression of one or more epithelial markers is often needed for diagnosis. In that regard, it is important to note that spindle cell carcinomas may only demonstrate focal (or no) immunoreactivity with antibodies directed against broad spectrum and low molecular weight cytokeratins (such as CAM5.2, AE1/AE3, or CK7 antibodies), and antibodies directed against high molecular weight cytokeratins (such as 34ßE12, CK 5/6, and CK14 antibodies) and p63 are often more sensitive in this setting (Fig. 4) $[7,8]$. One should also note that, in addition to epithelial markers, spindle cell carcinoma often expresses one or more mesenchymal markers such as vimentin and SMA. The histogenesis of spindle cell carcinoma remains controversial. However, recent immunohistochemical and genomic profiling studies indicate that these tumors are part of the spectrum of basal-like carcinomas and display a myoepithelial or epithelial to mesenchymal transition-like molecular make-up [9-11].

A peculiar variant of spindle cell carcinoma is the low grade, fibromatosis-like carcinoma. This is predominantly or almost completely composed of bland spindle cells [12, 13], and may either arise de novo or in association with a variety of benign fibrosclerotic lesions. Low grade, fibromatosis-like carcimoma has a favorable prognosis. Histologically, lesional cells closely resemble reactive fibroblasts (Fig. 4) such as those seen in fibromatosis and the diagnosis is usually dependant on the expression of cytokeratin or p63.

Given that the differential diagnosis of spindle cell carcinoma can potentially include any lesion with spindle cell morphology, any spindle cell lesion of the breast should be regarded as spindle cell carcinoma until proved otherwise, especially on needle core biopsy [14]. 
(a)

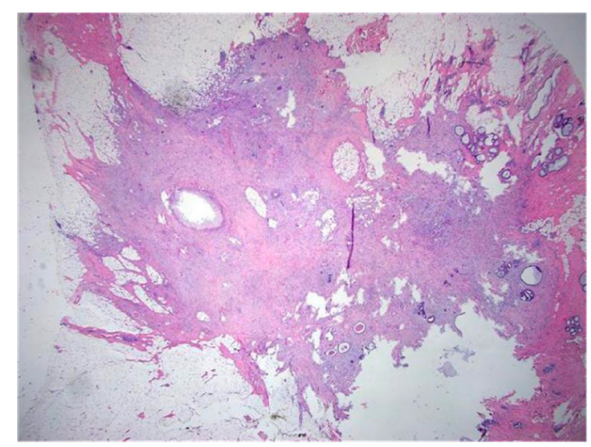

(b)

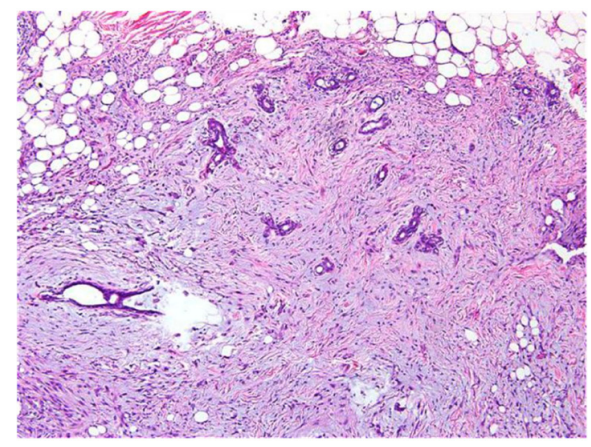

(c)

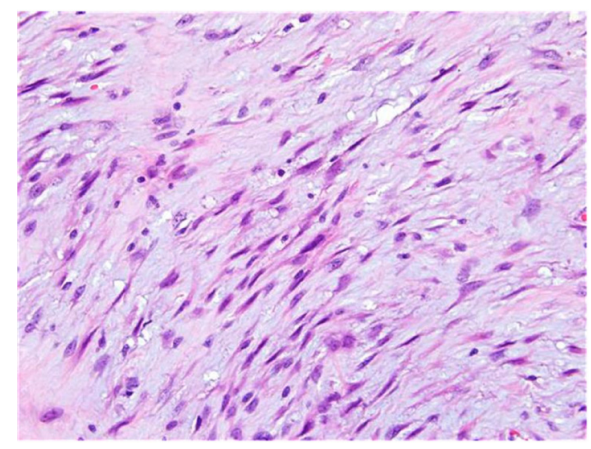

(d)

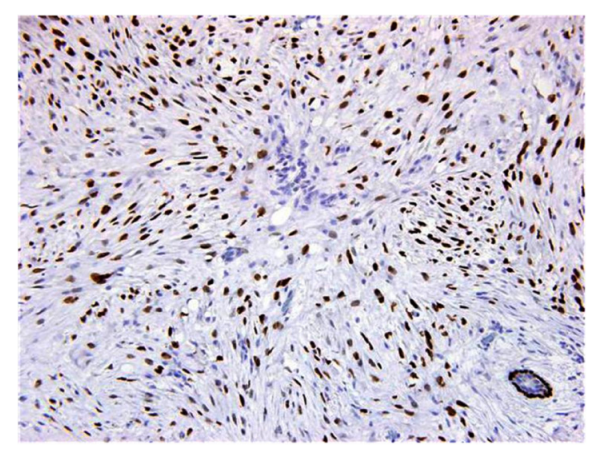

Fig. (4). Low-grade (fibromatosis-like) spindle cell carcinoma. This tumor, although somewhat well-circumscribed (a), is seen to infiltrate benign breast lobules (b), a finding that should raise suspicion of malignancy despite the somewhat bland nature of the tumor cells (c). The diagnosis was confirmed by immunohistochemistry which showed focal cytokeratin expression (not shown) and strong p63 expression (d) [hematoxylin and eosin, original magnification X20 (a); X100 (b); X400 (c) and immunoperoxidase X200 (d)].

\section{Pseudoangiomatous Stromal Hyperplasia}

Pseudoangiomatous stromal hyperplasia (PASH; also known as pseudoangiomatous hyperplasia of mammary stroma) is commonly an incidental microscopic finding in breast biopsies, but may present as nodular, palpable or mammographic mass lesions. The pathogenesis of PASH remains unclear, however, a hormonal etiology has been suggested. This is supported by the fact that PASH is common in men with gynecomastia, women during pregnancy, and older women on hormonal replacement therapy [15]. This lesion is characterized by the presence of dense collagenous, keloid-like stroma separated by slit-like, interanastomosing spaces lined by a single layer of flat spindle cells (or occasionally no cells) simulating vascular channels (Fig. 5). The term "pseudoangiomatous" was proposed to emphasize this histologic pattern, and the nonangioformative nature of the lesion. The proliferation of stromal elements is commonly intermixed with ducts or lobules. The space-lining spindle cells usually have a bland cytology but in more cellular examples of PASH may have a more plump appearance obscuring the pseudoangiomatous nature of the lesion. Component cells are also thought to be of fibroblastic/myofibroblastic origin as they are consistently immunoreactive with CD34 and SMA but negative for CD31 and factor VIII related antigen $[15,16]$. In fact, the myofibroblasts may occasionally aggregate into fascicles producing a pattern simulating myofibroblastoma (fascicular $P A S H)$ [16]. PASH may also been seen as a component in association with other lesions, particularly hamartomas, fibroadenomas and phyllodes tumors.

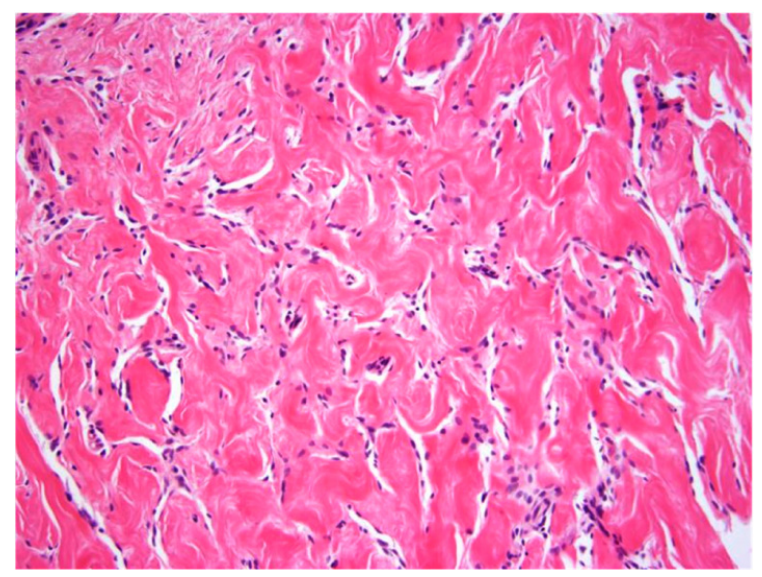

Fig. (5). Pseudoangiomatous stromal hyperplasia. This lesion is characterized by dense fibrous tissue in which slit-like spaces are evident. These spaces are lined by spindle cells resembling endothelium (hematoxylin and eosin, original magnification X200).

As one might expect, the main differential diagnosis of PASH is low-grade angiosarcoma. Features in favor of PASH include non-endothelial-lined spaces with no red blood cells (RBCs) and lack of lobular invasion. In contrast, angiosarcomas have endothelial-lined vascular channels with RBCs, and frequently infiltrate into the fat and the lobules. Atypical endothelial cells and mitotic figures are usually features of angiosarcoma but not of PASH. When in doubt, IHC for CD31 and CD34 can lead to a definitive diagnosis. Other vascular lesions of the breast, including hemangiomas and so-called "atypical vascular lesions" [17], are unlikely to 
be in the differential diagnosis of PASH because of their unequivocal vascular nature.

\section{Myofibroblastoma}

A rare benign lesion frequently seen in males, myofibroblastoma appears as a fascicular growth of bland spindle cells separated by hyalinized collagen bands. Several variants have been described, including cellular, collagenized, infiltrative, fatty, myxoid and epithelioid. The key distinguishing features include its small size and circumscription. Ducts/lobules are typically not involved, however, they may be occasionally entrapped (Fig. 6) [2].

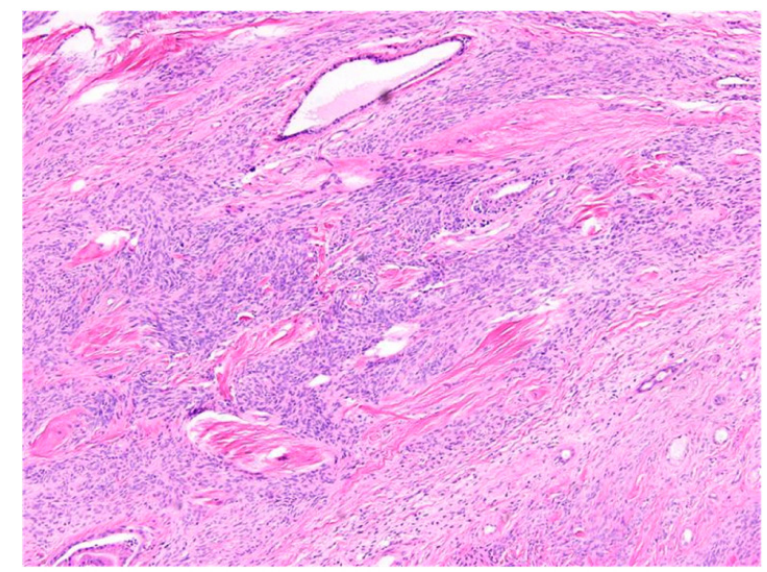

Fig. (6). Myofibroblastoma: This tumor is characterized by short fascicles of bland spindle cells separated by thick collagen bands. Note that a benign breast duct (upper third of image) is entrapped (hematoxylin and eosin, original magnification X200).

\section{Inflammatory Myofibroblastic Tumor}

Inflammatory myofibroblastic tumor (IMT) is extremely rare in the breast and usually presents as a nodular growth of myofibroblast-like cells in the background of a diffuse lymphoplasmacytic infiltrate and lymphoid follicles, as opposed to focal juxtatumoral lymphoid aggregates seen in fibromatosis. Inflammatory myofibroblastic tumor was originally considered to be an aberrant reactive and/or inflammatory response and was termed inflammatory pseudotumor; however, IMT has been recently shown to be a neoplastic process by evidence of its recurrence, metastasis, and clonal characteristics [18]. Of note, approximately $50 \%$ of these tumors are immunoreactive with ALK-1 [18].

\section{Reactive Spindle Cell Nodule}

Reactive spindle cell nodule (RSCN) is commonly seen at other sites, such as in the genitourinary tract and thyroid, with only a few publications documenting its presence in the breast despite frequent biopsy or surgical trauma in the breast [19-21]. It is characterized by a nodular, noncapsulated proliferation of plump spindle cells arranged in intersecting fascicles. The lesional cells (myofibroblasts) may show mild to moderate nuclear atypia and low mitotic activity, but no atypical forms. These lesions are usually small (up to $1 \mathrm{~cm}$ ), and frequently associated with the biopsy of papillary or complex sclerosing lesions [19]. Other biopsy-related changes, such as a mixed inflammatory infiltrate, hemosiderin deposition, foamy macrophages and rare giant cells are commonly present simultaneously. Sometimes normal epithelial elements may be entrapped into the proliferating spindle cells, leading to potential misinterpretation as a fibromatosis-like metaplastic carcinoma [19].

\section{Angiosarcoma}

Non-epithelial malignant spindle cell lesions are extremely rare in the breast. Angiosarcoma, either primary mammary or cutaneous, is the most common primary sarcoma in the breast, and is most frequently post-radiation in nature [22, 23]. The presence of interlacing/freelyanastamosing vascular channels is the key to its recognition (Fig. 7). Lining endothelial cells range from being quite bland in nature with only subtle atypia (mostly manifested as hyperchromasia only), to highly pleomorphic spindle cells. High grade tumors are more frequently solid with prominent necrosis. The presence of extensive hemorrhagic areas (socalled "blood lakes"), the identification of at least focal anastamosing vascular channels and the expression of endothelial markers by IHC, can be used to distinguish such high grade angiosarcomas from other high-grade sarcomas of the breast $[17,24]$.

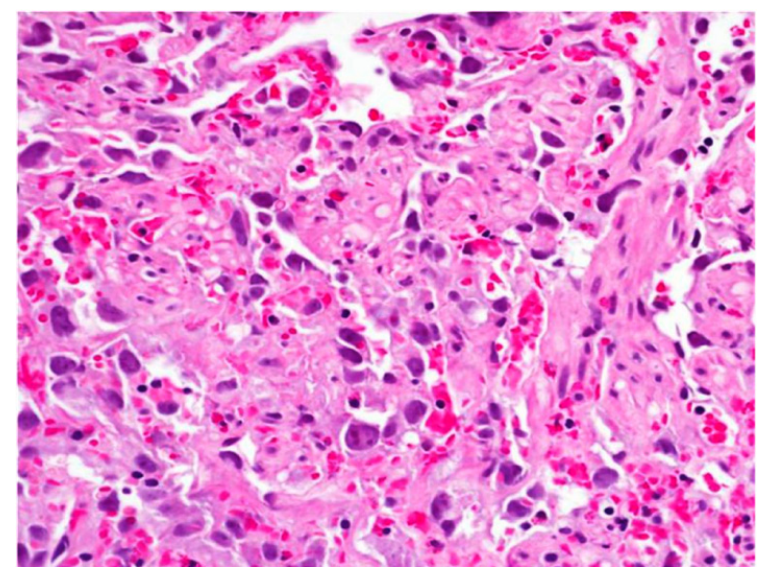

Fig. (7). Angiosarcoma. In this example, there are anastamosing slit-like vascular spaces lined by hyperchromatic, markedly atypical endothelial cells (hematoxylin and eosin, original magnification $\mathrm{X} 400$ ).

\section{Other Spindle-Cell Neoplasms}

There are many other primary spindle cell lesions that rarely arise in the breast, including solitary fibrous tumor/ hemangiopericytoma, dermatofibrosarcoma protuberans, leiomyosarcoma, fibrosarcoma, or malignant fibrous histiocytoma. Malignant melanoma, as well as many metastatic cancers, may also have spindle cell morphology. A detailed description of these entities is beyond the scope of this review. Finally, one should always remember that a spindle cell sarcoma identified on needle core biopsy of the breast may represent the stromal component of a malignant phyllodes tumor, which should be considered in the differential diagnosis.

\section{SUMMARY}

Spindle cell lesions of the breast represent a diverse group of reactive and neoplastic entities with overlapping histomorphology, potentially leading to diagnostic difficulty especially in needle core biopsy material. The two most important differential diagnostic considerations are spindle cell (metaplastic) carcinoma and the stromal component of a phyllodes tumor. Careful histologic examination in 
Table 1. Salient Features of Major Spindle Cell Lesions of the Breast

\begin{tabular}{|c|c|}
\hline Lesions with Predominantly Bland Spindle Cells & Key Features \\
\hline $\begin{array}{l}\text { - } \text { Spindle cell carcinoma } \\
\text { - } \text { Scars } \\
\text { - } \text { Mammary fibromatosis } \\
\text { - } \\
\text { - } \\
\text { PASHular fasciitis } \\
\text { - } \\
\text { Myofibroblastoma }\end{array}$ & $\begin{array}{ll}\text { - } & \text { Expression of cytokeratins or p63 } \\
\text { - } & \text { History of trauma/procedure and presence of biopsy site-associated changes } \\
\text { - } & \text { Long fascicles; nuclear } \beta \text {-catenin IHC staining } \\
\text { - } & \text { Well circumscribed; tissue culture-like fibroblasts; myxoid stroma; extravasated RBC } \\
\text { - } & \text { Collagenous stroma separated by slit-like, interanastomosing spaces lined by spindle cells } \\
\text { - } & \text { Fascicular growth separated by hyalinized collagen bands; circumscription }\end{array}$ \\
\hline Lesions with Pleomorphic Spindle Cells & Key Features \\
\hline $\begin{array}{l}\text { - } \text { Spindle cell carcinoma } \\
\text { - } \quad \text { Malignant phyllodes tumor } \\
\text { - } \text { Angiosarcoma } \\
\text { - Other malignant spindle-cell neoplasms }\end{array}$ & 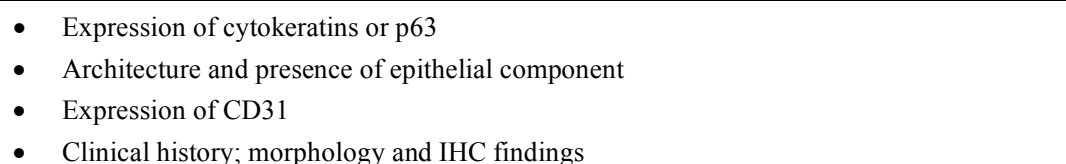 \\
\hline
\end{tabular}

conjunction with the judicious use of IHC is required in order to reach a correct diagnosis. A definitive diagnosis may be impossible in biopsies with a limited amount of tissue. The salient features of most spindle-cell lesions of the breast are summarized in Table $\mathbf{1}$.

\section{REFERENCES}

[1] Glazebrook KN, Reynolds CA. Mammary fibromatosis. AJR Am J Roentgenol 2009; 193: 856-60.

[2] McMenamin ME, DeSchryver K, Fletcher CD. Fibrous lesions of the breast: A review. Int J Surg Pathol 2000; 8: 99-108.

[3] Abraham SC, Reynolds C, Lee JH, et al. Fibromatosis of the breast and mutations involving the APC/beta-catenin pathway. Hum Pathol 2002; 33: 39-46.

[4] Evans H, Bridge JA. Nodular fasciitis. In: Fletcher CDM, Unni KK, Mertens F, Eds. Tumours of soft tissue and bone. France, Lyon: IARC Press 2002; pp. 48-9.

[5] Tse GM, Tan PH, Lui PC, Putti TC. Spindle cell lesions of the breast-the pathologic differential diagnosis. Breast Cancer Res Treat 2008; 109: 199-207.

[6] Lee AH. Recent developments in the histological diagnosis of spindle cell carcinoma, fibromatosis and phyllodes tumour of the breast. Histopathology 2008; 52: 45-57.

[7] Koker MM, Kleer CG. p63 expression in breast cancer: a highly sensitive and specific marker of metaplastic carcinoma. Am J Surg Pathol 2004; 28: 1506-12.

[8] Carter MR, Hornick JL, Lester S, Fletcher CD. Spindle cell (sarcomatoid) carcinoma of the breast: a clinicopathologic and immunohistochemical analysis of 29 cases. Am J Surg Pathol 2006; 30: 300-9.

[9] Leibl S, Gogg-Kammerer M, Sommersacher A, Denk H, Moinfar F. Metaplastic breast carcinomas: are they of myoepithelial differentiation? immunohistochemical profile of the sarcomatoid subtype using novel myoepithelial markers. Am J Surg Pathol 2005; $29: 347-53$.

[10] Reis-Filho JS, Milanezi F, Steele D, et al. Metaplastic breast carcinomas are basal-like tumours. Histopathology 2006; 49: 1021.
[11] Weigelt B, Kreike B, Reis-Filho JS. Metaplastic breast carcinomas are basal-like breast cancers: a genomic profiling analysis. Breast Cancer Res Treat 2009; 117: 273-80.

[12] Gobbi H, Simpson JF, Borowsky A, Jensen RA, Page DL. Metaplastic breast tumors with a dominant fibromatosis-like phenotype have a high risk of local recurrence. Cancer 1999; 85: 2170-82.

[13] Sneige N, Yaziji H, Mandavilli SR, et al. Low-grade (fibromatosislike) spindle cell carcinoma of the breast. Am J Surg Pathol 2001; 25: 1009-16.

[14] Schnitt SJ, Collins LC. Spindle cell lesions. In: Biopsy interpretation of the breast. Philadelphia: Wolters Kluwer/Lippincott Williams \& Wilkins 2008; pp. 323-43.

[15] AbdullGaffar B. Pseudoangiomatous stromal hyperplasia of the breast. Arch Pathol Lab Med 2009; 133: 1335-8.

[16] Powell CM, Cranor ML, Rosen PP. Pseudoangiomatous stromal hyperplasia (PASH). A mammary stromal tumor with myofibroblastic differentiation. Am J Surg Pathol 1995; 19: 270-7.

[17] Brenn T, Fletcher CD. Radiation-associated cutaneous atypical vascular lesions and angiosarcoma: clinicopathologic analysis of 42 cases. Am J Surg Pathol 2005; 29: 983-96.

[18] Coffin CM, Fletcher JA. Inflammatory myofibroblastic tumour. In Fletcher CDM, Unni KK, Mertens F, Eds. Tumours of Soft Tissue and Bone. France, Lyon: IARC Press 2002; pp. 91-3.

[19] Gobbi H, Tse G, Page DL, Olson SJ, Jensen RA, Simpson JF. Reactive spindle cell nodules of the breast after core biopsy or fineneedle aspiration. Am J Clin Pathol 2000; 113: 288-94.

[20] Reis-Filho JS, Schmitt FS. Reactive spindle cell nodules of the breast. Am J Clin Pathol 2001; 115: 781-2.

[21] Garijo MF, Val-Bernal JF, Vega A, Val D. Postoperative spindle cell nodule of the breast: Pseudosarcomatous myofibroblastic proliferation following endo-surgery. Pathol Int 2008; 58: 787-91.

[22] Scow JS, Reynolds CA, Degnim AC, Petersen IA, Jakub JW, Boughey JC. Primary and secondary angiosarcoma of the breast: The Mayo Clinic experience. J Surg Oncol 2010; 101(5): 401-7.

[23] Biswas T, Tang P, Muhs A, Ling M. Angiosarcoma of the breast: a rare clinicopathological entity. Am J Clin Oncol 2009; 32: 582-6.

[24] Nascimento AF, Raut CP, Fletcher CD. Primary angiosarcoma of the breast: clinicopathologic analysis of 49 cases, suggesting that grade is not prognostic. Am J Surg Pathol 2008; 32: 1896-904.

(C) Wei and Hameed; Licensee Bentham Open.

This is an open access article licensed under the terms of the Creative Commons Attribution Non-Commercial License (http://creativecommons.org/licenses/by-nc/ 3.0/) which permits unrestricted, non-commercial use, distribution and reproduction in any medium, provided the work is properly cited. 